\title{
Research and Practice on Convergence and Promotion of Learning Group and Knowledge Management
}

\author{
Xiao-dong Zheng ${ }^{12, \mathrm{a}}$ and Han-hui Hu ${ }^{1, \mathrm{~b}}$ \\ ${ }^{1}$ School of Economics and Management, Southeast University, P.R.China \\ 2 Jiangsu Power Design Institute Co., Ltd., P.R.China \\ a51847986@163.com, bhuhh@seu.edu.cn
}

Keywords: Knowledge Management; Learning Group; Power Design Enterprise

\begin{abstract}
The paper first studies the convergence of learning groups and knowledge management, pointing out that learning is process of knowledge production, and the existent knowledge has influence on future learning. The relationship between Learning and knowledge is interlaced and promoted. As the similarities between them make the integration possible and complementary differences make that necessary. Next, it proposes the knowledge classification system of power design institute according to its knowledge features. Then it studies the methods, techniques and tools of knowledge management during the capacity-building process of learning groups. Finally, this paper introduces the realization of knowledge management system.
\end{abstract}

\section{Introduction}

The power design enterprises usually have more than 20 specialties including electrical engineering, architecture etc. and set up the work groups which are composed of highly educated, skilled, high-quality members from the same specialty or similar specialties. Moreover, the production process is to input information, process information and finally generate knowledge, which only has information flow but no material flow. Therefore, the work group in such knowledge-intensive enterprises is a typical learning group, and its knowledge management centered on the knowledge assets is an important activity of capacity-building process. This paper studies the integration of learning groups in power design enterprises and knowledge management. Knowledge management theory and method system are carried into the construction of learning groups, which is aimed to increase the growth of work groups and the production efficiency.

\section{The Learning Group and Knowledge Management}

\subsection{Learning Group and Knowledge Management}

Learning team is a team that members can consciously, systematically and continuously acquire knowledge, improve behavior, optimize the team system ${ }^{[1]}$. The learning group, as a kind of learning team, is also characterized by systematism, conscious learning, and constant revision, harmonious and healthy development of members and so on.

Knowledge is the source of enterprise competitiveness but itself does not produce value. For enterprises, knowledge can be used to generate value though management and utilization. Knowledge management is defined as a process that creating, acquiring and utilizing knowledge in order to enhance the performance of the organization ${ }^{[2]}$. Knowledge management ensures that the most needed knowledge can be delivered to the people most in need at the most needed time ${ }^{[3]}$. Knowledge management is the management of a series of activities and processes, so as to maximize the value of knowledge and enhance organizational competitiveness ${ }^{[4]}$. Knowledge management is the planning and management activity of knowledge, knowledge creation and knowledge application ${ }^{[5]}$.

\subsection{Theoretical Study on the Integration of Leaning Group and Knowledge Management}

Both the learning group and knowledge management highlight the dominant position of knowledge in the organization, but they differ in perspective, model, management and other aspects. 
Learning group emphasizes creating the learning atmosphere in organization and improving individual behavior, in order to promote the group through the combination between personal learning and organizational learning. Whereas knowledge management attaches importance to the way in which knowledge exists and the process of activity in the organization, emphasizing knowledge acquisition, participation and innovation ${ }^{[6]}$. Learning is process of knowledge production, and the existent knowledge has influence on future learning. The relationship between Learning and knowledge is interlaced and promoted, and it provides the entry point for the integration ${ }^{[7]}$. Therefore, the similarities between them make the integration possible and complementary differences make it necessary.

Knowledge and learning always run through the construction of working group. On the one hand, we can rely on learning group theory to create a learning group as the key point to promote the construction of working group. Many methods can be adopted, such as creating a good environment, establishing the incentive mechanism, guiding employees to combine the position and the learning, to achieve the organic integration and mutual promotion between work and learning. On the other hand, we can rely on knowledge management theory to implement knowledge management for the working group. Specifically, knowledge possessed by every working group should be extracted, sorted and classified. Then we use knowledge management techniques and tools to combine the rearranged knowledge with production management system to enhance personal or group performance, which employees can acquire, store, share, apply and create knowledge during work. Therefore, both learning groups and knowledge management supplement each other.

\section{Knowledge Management System of Learning Groups in Power Design Enterprise}

\subsection{Knowledge Classification of Learning Groups}

The scientific classification of the group knowledge can effectively save and maintain the knowledge generated by the groups, help the staff to retrieve the required knowledge resources quickly and accurately, so it is conducive to sharing, learning and delivering knowledge. According to the characteristics of power design enterprises, the knowledge from the working group level is divided into two categories: standard specification and professional business construction content.

1. Enterprise standard specification system generally consists of technical standards, management standards and work standards. For the work group, its regulatory regime is further refined according to the enterprise standard specification, so it is more operational and appropriate. The classification is shown in Table 3-1.

Table 3-1 Classification of Standard Specification

\begin{tabular}{|c|c|}
\hline $\begin{array}{l}\text { Categor } \\
\mathrm{y}\end{array}$ & Sub Category \\
\hline $\begin{array}{l}\text { Technic } \\
\text { al } \\
\text { standar } \\
\text { d }\end{array}$ & $\begin{array}{l}1 \text { Valid version of technical standards for each group } \\
2 \text { Technical standards and regulations of enterprise, superior } \\
\text { departments and related parties required to be implemented }\end{array}$ \\
\hline $\begin{array}{l}\text { Manage } \\
\text { ment } \\
\text { standar } \\
\text { d }\end{array}$ & $\begin{array}{l}1 \text { Enterprise management standards, documents related to QSH, } \\
\text { function management standards, function management } \\
\text { standards and management aviso required to be implemented. } \\
2 \text { Regulations and requirements of superior department required } \\
\text { to be observed. } \\
3 \text { Comprehensive Laws, regulations and standards or related to } \\
\text { Production Safety. }\end{array}$ \\
\hline $\begin{array}{l}\text { Workin } \\
\text { g } \\
\text { standar } \\
\text { d }\end{array}$ & $\begin{array}{l}1 \text { Working standards for management personnel. } \\
2 \text { Working standards for production operation personnel. } \\
3 \text { Working standards for production business role. }\end{array}$ \\
\hline $\begin{array}{l}\text { Regulat } \\
\text { ory } \\
\text { regime }\end{array}$ & $\begin{array}{l}1 \text { Work duties for director of working group and Chief Engineer } \\
2 \text { Performance appraisal and distribution of working group. } \\
3 \text { Annual performance assessment of working group, } \\
\text { agreements of safety responsibility. }\end{array}$ \\
\hline
\end{tabular}


2. Professional business construction and learning activity are important knowledge activity. Business construction achievements, as the core content of knowledge management, play an important role in guiding designer technically, helping improve design quality and efficiency. The classification is shown in Table 3-2.

Table 3-2 Classification of Professional Business Construction

\begin{tabular}{|c|c|}
\hline Category & Sub Category \\
\hline Design Manual & $\begin{array}{l}\text { Universal Manual, Project Manager Handbook, Professional } \\
\text { Design Discipline, Design Review Outline }\end{array}$ \\
\hline $\begin{array}{l}\text { Professional } \\
\text { Template }\end{array}$ & $\begin{array}{l}\text { Work Plan, Standard Volume Catalogue, Volume Task book, } \\
\text { Job Instruction, Technical Specification of equipment, } \\
\text { Provide Information, Calculation Sheet, Design Review } \\
\text { Summary, Design Summary, Survey Mission }\end{array}$ \\
\hline $\begin{array}{l}\text { Quality } \\
\text { information }\end{array}$ & $\begin{array}{l}\text { Quality Analysis Card, Quality Information Feedback, } \\
\text { Product Quality Inspection, QC Group harvest }\end{array}$ \\
\hline $\begin{array}{l}\text { Design Atlas/ } \\
\text { Typical Design }\end{array}$ & $\begin{array}{llll}\text { Standard Gallery, } & \text { Standard } & \text { Atlas, } & \text { Typical } \\
\text { Design(Standardized Design), Project } & \text { Bidding } & \text { Subject, } \\
\text { Materials of Project Appraisal for Excellent } & \\
\end{array}$ \\
\hline Product Literature & Product Sample、Vender Materials \\
\hline $\begin{array}{l}\text { Intellectual } \\
\text { Property }\end{array}$ & $\begin{array}{l}\text { Scientific and Technological achievements, Patents and } \\
\text { Proprietary Technology, Software Copyright, Professional } \\
\text { Thesis, Professional Technical Summary }\end{array}$ \\
\hline Informatization & Professional Software,Digital Design,MIS \\
\hline $\begin{array}{l}\text { Learning/Training/ } \\
\text { Meeting }\end{array}$ & $\begin{array}{l}\text { Training and Professional Learning, Outside Learning, } \\
\text { Outside Professional Meeting, Outside Investigation, } \\
\text { Searching Results }\end{array}$ \\
\hline $\begin{array}{l}\text { Experience } \\
\text { Exchange }\end{array}$ & $\begin{array}{l}\text { Discussion and Exchange, Knowledge extracted from tools } \\
\text { which can externalize tacit knowledge, such as Knowledge } \\
\text { Forum, Knowledge Q\&A, Knowledge Expert, Knowledge } \\
\text { Circle etc. }\end{array}$ \\
\hline Reference & Design Reference \\
\hline
\end{tabular}

\subsection{Knowledge Management System of Learning Group}

In order to improve the performance, the Knowledge Management of Learning Group based on the knowledge resources of the group, carries out a series of management activities such as acquisition, storage, sharing, transmission, application and creation. It can be divided into enterprises, departments, groups, individuals and projects level.

The core process of knowledge management consists of activities such as knowledge acquisition, storage, sharing, delivery, application and creation. In addition, Knowledge management includes the methods and tools which can advance the overall core process ${ }^{[8]}$. During the construction activities of learning group, methods, techniques and tools can be used to operate all knowledge activities, in order to promote the implementation of knowledge management. The specific application is as follows.

1) Build harmonious group culture to create an environment conducive to knowledge sharing and delivery

Harmonious group culture can create situation and atmosphere in which members share and perceive collectively. It is not only in favor of establishing trust and respect among members, making them helpful and united, but also clear the obstacles in communication, promoting the sharing and transmission of knowledge, especially the tacit knowledge. In SECI model, "the socialized process that transforming the explicit knowledge into the tacit knowledge”, is a process which creating the tacit knowledge through common experiences, such as sharing thinking pattern 
and implicit skills. The key point of acquiring tacit knowledge is the "experiences", especially the "Common Experiences"[9].

2) Build professional knowledge portal to a construct knowledge database for storage and sharing

Knowledge and experiences, such as Design Instruction, Design Review Outline, Mandatory Provisions, FAQ for Construction Drawing and Design File Templates etc., should not only be stored, maintained and updated constantly, but also need a convenient channel to share and transmit to be utilized effectively. The Professional knowledge portal is created by each working group based on the classification described above, including Design Tools, Design References, Quality Information and other professional knowledge. Each director of working groups is in charge of these knowledge portals which play an important part in learning for employees.

3) Build professional knowledge forum to open up knowledge channels for exchange and transmission

The forms of Knowledge in forum are more varied and free, covering large scope ranging from cognition and understanding of technical issues to personal experience of design projects. Especially, the tacit knowledge like employees' insights, understandings, experiences, are easy to share and communicate. The technical director served as forum manager is responsible for forum layout, members and maintaining materials. While the business backbones, as the moderator of each section, take responsibility for the content and quality of articles, ensuring the correctness and seriousness of the knowledge. As for the professional knowledge portal, the forum can be a helpful complement, as the forum manager can regularly summarize the essence of the forum knowledge and add them to the portal as the explicit formal knowledge.

4) Build special technical groups to promote knowledge creation and innovation based on sharing

The working group can use the theory of entity knowledge community to lead employees to compose special technical research group. The scale of knowledge community is 3-6 people generally, including expertise and staff having common interest. Because of the common interest and desire, members are inspired to learn and research purposefully, and participate forwardly. This will not only enable the special technical knowledge to spread and transfer in the group, reducing the risk of knowledge loss, but also inspire members to speed up the creation and innovation of knowledge though exchange and mutual complement of knowledge.

There are many other knowledge management applications in the working group, such as professional business learning, Mentorship Training, E-Learning and Personal Knowledge Management etc., will not be introduced one by one in this paper.

\section{Conclusion}

This paper concludes that the learning group and the knowledge management complement and promote each other. On the one hand, we rely on the theory of the learning group to promote the construction of working group. On the other hand, the knowledge management theory can be used to instruct the work and construction of learning group. Then based on the knowledge characteristics of power design enterprise, we put forward the knowledge classification from the working group level. Finally, combing the methods, techniques and tools of knowledge management, we introduce the practical activities in the implementation of knowledge management, which has good results.

\section{References}

[1] CHEN Guoquan. Team Learning and Learning Teams: Their Concepts, Measurements and Impacts on Team Performance, and the Capability Model s [J]. Chinese Journal of Management, 2007,4(5):602-609.

[2] Bassi.Harnessing the Power of Intellectual Capital[J].Training and Development,1997,51(12): 25-30. 
[3] ZUO Meiyun, XU Ke, CHEN Yu. On the Content Framework of Enterprise Knowledge Management [J]. Journal Of Renmin University Of China, 2003(5):69-76.

[4] CEN. European Guide to good Practice in Knowledge Management - Part 1: Knowledge Management Framework: WA 14924-1[S].Brussels: the CEN Management Centre, 2004:6.

[5] China National Institute of Standardization. Knowledge Management Part 1: Framework .GB/T 23703.1-2009 [S].Standards Press of China, 2009:1.

[6] WU Yan, CAO Weiping. On convergence of Knowledge Management and Learning Organization [J].Science \& Technology Review, 2004(8):36-38.

[7] LONG Jing. Convergence and Review of Organization Learning and Knowledge Management [J]. Science and Technology Management Research, 2008(12):505-508.

[8] Kai Mertins, Peter Heisi, Jens Vorbeck. Knowledge Management: Concepts and Best Practices (2nd Edition) [M] Springer Science \& Business Media. 2003.

[9] LIANG Linmei, SUN Junhua. Knowledge Management [M]. Peking University Press,2011:10 